communist faction in the Duma, the Russian parliament, and a stalwart champion of Soviet ideals. "Alferov is a scientist of the highest repute - but his views are not always forward-looking," says Severinov.

At a meeting in April of the Council for Science and Education, a presidential advisory body chaired by Vladimir Putin, Alferov agreed with academicians who reject the use of bibliometric indicators such as numbers of research papers and the impact factors of the journals in which they are published - for measuring scientific performance. He agreed that such assessments would encourage Russian scientists to publish their best work in foreign highimpact journals rather than in Russian ones.

Such nationalistic views threaten to cement the isolation of Russian science further, says Mikhail Feigel'man, deputy director of research at the academy's Landau Institute for Theoretical Physics near Moscow. (Feigel'man himself is not a member of the academy and will not be voting on 29 May.) "Our ties with international science are all but eliminated," he says. "We're caught in a system that was constructed in Soviet times when academic exchange was not considered important. But now it is."

Travel grants are almost unavailable to RAS researchers, and foreign scientists or students are absent at many academy institutes. "Anyone interested in working with us, or giving talks at our institute, I have to tell that it is not possible unless they come with their own money," says Feigel'man. Meanwhile, low salaries, lack of grant money and poor career prospects are deterring Russian talent from pursuing science at home, he says. "Our own people leave Russia as fast as they can."

The Russian government itself seems to view the RAS as increasingly irrelevant. The academy's budget, around 60 billion roubles (US $\$ 1.9$ billion) per year, has stagnated since 2000, even as overall science spending in Russia has doubled (see 'Flatlining'). The government is funnelling the new money into university research and ventures such as the Skolkovo, a new science complex that will focus on biotechnology and information technology, among other disciplines, in partnership with international companies. German engineering and electronics giant Siemens, based in Munich, and Finnish mobile-phone company Nokia, in Helsinki, have already signed up to participate.

Science minister Dmitri Livanov has said that he expects a thorough overhaul of the academy and that productivity should become a funding prerequisite for RAS institutes and scientists. "There are some researchers who fully meet this standard," Livanov said in a 2012 interview. "Those who do not work we will have to call something different." -

\section{A RISKY REGION}

Geoscientists are installing 69 Global Position System stations across the Caribbean in an effort to monitor earthquakes and other hazards.
Completed stations Planned stations

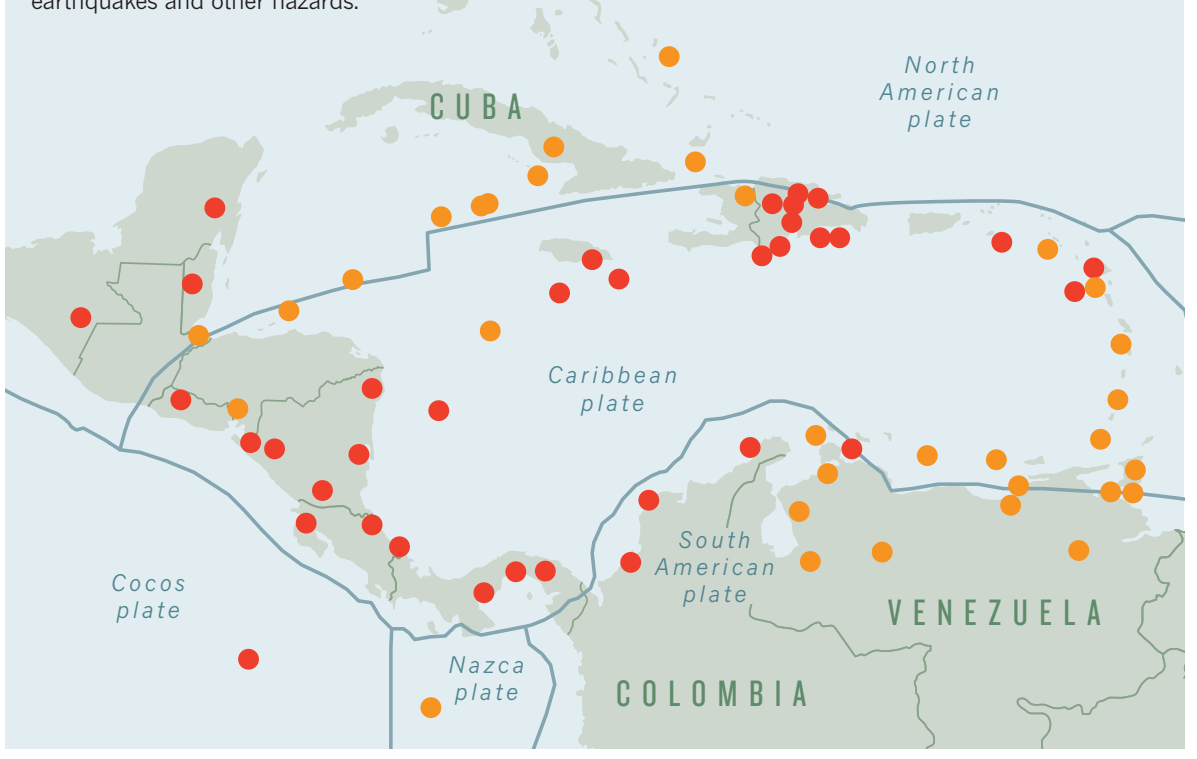

GEOPHYSICS

\title{
A network to track Caribbean hazards
}

\section{Multi-nation effort is a test of scientific diplomacy.}

\section{BY ALEXANDRA WITZE IN CANCÚN, MEXICO}

$O^{\circ}$ ome US geophysicists are going where few of their compatriots have gone before: to Cuba, Venezuela and other countries that are notoriously anti-American. But these countries are also notoriously plagued by natural disasters such as earthquakes, and so engineers are blanketing the Caribbean with a network of sensors to detect the crustal strains and brewing storms that threaten the region.

Early results from the US\$6-million system, called the Continuously Operating Caribbean GPS Observational Network (COCONet) and funded by the US National Science Foundation (NSF), were presented in Cancún, Mexico, on 17 May at the American Geophysical Union Meeting of the Americas. COCONet is an offshoot of another NSF effort that, over the past decade, has sprinkled Global Positioning System (GPS) sensors across the western United States. That was child's play compared with working across 31 separate national governments, many of which distrust the United States, says Glen Mattioli, a programme director at UNAVCO, a geodetic-survey organization based in Boulder, Colorado, that is managing the project.

Under COCONet, geoscientists across the
Caribbean are gaining free access to data that will help them to understand and prepare for natural hazards such as earthquakes and hurricanes. But unless they adopt the network as the long-term backbone for observations in the region, the project could go down as just another well-meaning but failed effort to bridge national differences and develop scientific capacity. To most, it is worth the risk. "If you don't bet, you don't win," says Franck Audemard, a geologist at the Venezuelan Foundation for Seismological Research in Caracas.

COCONet stations are being set up at sites as diverse as steep rainforest slopes and isolated coral-reef islands (see 'A risky region'). Each station contains meteorological instruments, along with a GPS unit that constantly monitors ground movements and, in many cases, transmits those data in near real time. So far, UNAVCO has built or upgraded 38 of its planned 69 sites. At least 61 existing stations are also being incorporated into the network.

The project has made more progress than expected in acquiring the permits needed to set up stations, says Mattioli. That holds true even in Cuba, where officials have already approved the COCONet stations slated to arrive in June, even as US officials are still working 
through the permissions, Mattioli says.

Spurred on by the devastating 2010 Haiti quake, the network aims to fill out the currently patchy picture of the region's geological turmoil. Off the Pacific coast of Costa Rica, for instance, a COCONet station on the isolated Isla del Coco is the only GPS station continuously tracking the Cocos plate as it dives beneath the Caribbean plate. The data show that the two plates are converging at a rate of 78 millimetres per year. Such information will help geophysicists to reconcile their ideas about plate motion in the region, says Marino Protti, a geologist at the National University of Costa Rica in Heredia, who presented his findings in Cancún.

Other COCONet stations dot Costa Rica's Nicoya Peninsula, one of the few places on land that lie directly above a subduction zone. In
September 2012, Nicoya shuddered from a magnitude-7.6 earthquake. "Having the network helped us see that it was not a whole-plate event," Protti says. He thinks that remaining stress in the plate could trigger another large tremor.

Besides tracking movements in Earth's crust, the GPS data allow atmospheric scientists to measure how much water vapour sits in the air between each station and the GPS satellites, based on the delay in the signal's travel time. That information is a rare, real-time glimpse of how much water is available to power hurricanes, says meteorologist John Braun of the University Corporation for Atmospheric Research in Boulder.

COCONet is even yielding some unexpected societal benefits. In the Dominican Republic, land surveyors are eagerly using the nation's nine stations to comply with a real-estate law that requires precise surveying of parcels of land for sale, says Alexander Holsteinson of the National University of Pedro Henríquez Ureña in Santo Domingo.

Yet funding for COCONet runs out in 2015, and no one knows what will happen then. Each country will have to find the money to keep its stations operating, says Guoquan Wang, a geophysicist at the University of Houston, Texas, and a COCONet member who developed a GPS network for Puerto Rico and the Virgin Islands. That means that host nations will have to find value in supporting the project, says Héctor Mora Páez, who heads the GPS network for the Colombian Geological Survey in Bogota. "You have to make the local people feel involved." -
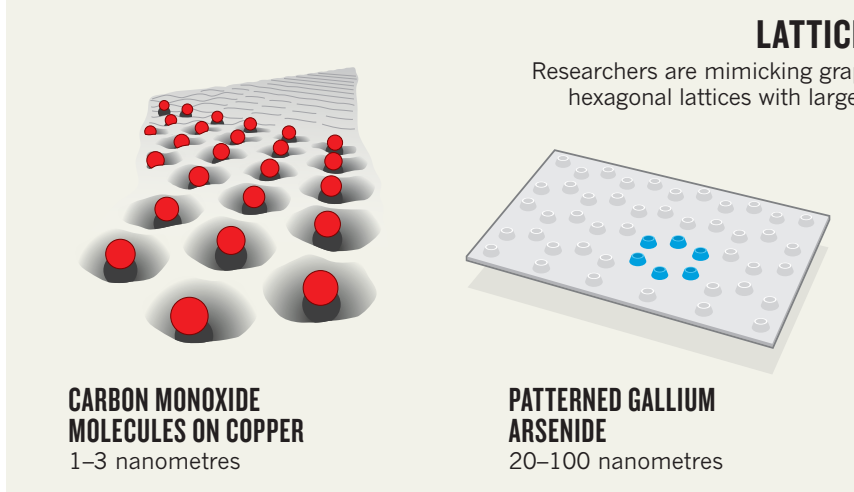

LATTICE LOOKALIKES

20-100 nanometres

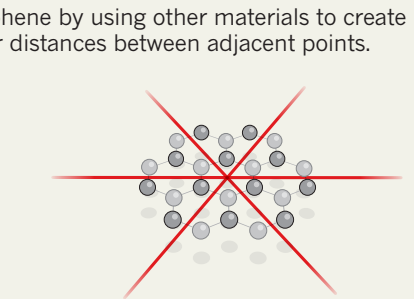

POTASSIUM ATOMS

TRAPPED BY LASERS

500 nanometres

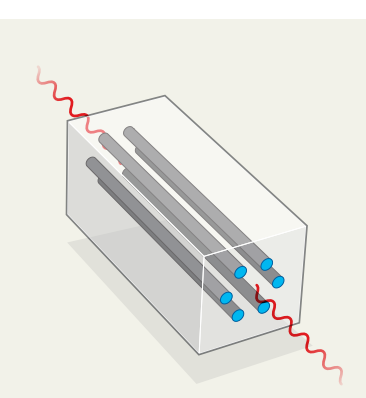

MICROWAVES BETWEEN CERAMIC CYLINDERS

15 millimetres

\section{Graphene knock-offs probe ultrafast electronics}

\section{Honeycomb lattices in different materials enable experiments impossible in the real thing.}

\section{BY EUGENIE SAMUEL REICH}

$\mathrm{I}$ f imitation is the sincerest form of flattery, then graphene is basking in admiration. Several labs are recreating the six-fold geometry of the carbon-based material with a range of building blocks, hoping to match - if not surpass - graphene's fascinating properties.

The approaches span a range of length scales, from nanometres to millimetres (see 'Lattice lookalikes'), and take advantage of a variety of construction techniques, including potassium atoms trapped by laser beams, hexagons etched on a gallium arsenide surface and microwaves pumped into a honeycomb arrangement of ceramic cylinders. The research is mostly motivated by curiosity, and few think that any of the 'artificial graphenes' will be used in applications. But the new materials show that hexagonal patterns are worth investigating. "It's clear the physics in electrons in graphene is very attractive," says Eros Mariani, a theoretical physicist at the University of Exeter, UK.

Graphene has unusual electronic properties as a result of its Dirac points, positions in its single-sheet honeycomb lattice of carbon atoms at which the energy bands of electrons from adjacent atoms link up. These allow electrons in the bands to speed across the material, like cars changing roads at major intersections instead of getting stuck on one jammed road. Measurements reported ${ }^{1,2}$ in 2005 confirmed that electrons in graphene move so fast that they seem to have no mass, and are, in effect,

moving at the speed of light. That fuelled hopes that graphene could be used to make ultrafast electronics; it also set the stage for the discovery of exotic quantum-mechanical effects.

In 2010, physicist Hari Manoharan, an expert in atomic manipulation at Stanford University in California, stumbled on the first graphene mimic. Manoharan and his team were using a scanning tunnelling microscope to arrange various molecules on a copper surface when they were struck by a hexagonal pattern. It looked

$\rightarrow$ NATURE.COM For more on the properties of graphene, visit: go.nature.com/hm $41 \mathrm{sm}$ uncannily like graphene but was eight times larger in scale. "We were thinking, why don't we see if it has graphene's properties?" says Manoharan. 